\title{
A transnational marine ecological observatory in the Adriatic Sea to harmonize a fragmented approach to monitoring and conservation
}

\author{
Elisabetta Manea, ${ }^{1}$ Caterina Bergami,${ }^{2 *}$ Lucia Bongiorni, ${ }^{1}$ Lucilla Capotondi, ${ }^{2}$ Elisabeth De Maio, ${ }^{1}$ Alessandro Oggioni, ${ }^{3}$ \\ Alessandra Pugnetti ${ }^{1}$ \\ ${ }^{1}$ Institute of Marine Sciences, National Research Council, ISMAR-CNR, Arsenale, Tesa 104, Castello 2737/F, 30122 Venice; ${ }^{2}$ Institute \\ of Marine Sciences, National Research Council, ISMAR-CNR, Via Piero Gobetti 101, 40129 Bologna; ${ }^{3}$ Institute for electromagnetic \\ sensing of the environment, National Research Council, IREA-CNR, Via Bassini 15, 20133 Milan, Italy
}

\begin{abstract}
The design and establishment of Marine Ecological Observatories (MEOs) are fostered at the European level. MEOs should adopt a holistic view, integrating and harmonizing long-term oceanographic and ecological research and monitoring, and increasing conservation strategies effectiveness according to the ecological connectivity concept. The data and knowledge collected and made available through MEOs should inform policies dealing with conservation and management of the marine environment. We present and discuss these issues in the Adriatic Sea context, where the transnational ecological observatory "ECOAdS" is under development in the framework of the Interreg Italy-Croatia project ECOSS (Observing System in the Adriatic Sea: oceanographic observations for biodiversity), which aims to support Natura 2000 network implementation and cross-border coordination of multiple monitoring initiatives. We analyse the main EU directives that deal with marine conservation, notably the Habitats and Birds directives, the Water Framework Directive, and the Marine Strategy Framework Directive, as they are the primary instruments that can guide the development of the observatory while strengthening cooperation at the basin scale. We bring out the synergies and discrepancies among these legal instruments and build on them ECOAdS as a monitoring platform that may respond and contribute to their requirements, boosting the synergies and overcoming the weaknesses. Finally, we provide some hints for the further development of this transnational MEO as a collector of the existing monitoring efforts aimed at harmonizing their approaches and incorporating the ecological connectivity to foster an ecosystem-based approach to conservation management.
\end{abstract}

\section{INTRODUCTION}

The need of systematic scientifically based monitoring programs is central for the management of the marine environment, which is facing salient alterations due to increasing and cumulative human impacts and the changing global climate (Bax et al., 2018; Miloslavich et al., 2018; McQuatters-Gollop et al., 2019). The establishment and implementation of integrated, harmonized and extended monitoring systems and infrastructures have been also recognized as crucial for the achievement of the United Nation Sustainable Development Goals (SDGs), especially the UN SDG 14 "Life below water" (Biermann et al., 2017) and the effective protection and restoration of the marine environment (Mack et al., 2020).

Stemming from these emerging needs, Marine Observing systems (MOs) have spread globally as integrated observing and experimenting infrastructures able to monitor oceanographic variables and to collect high-resolution data in selected marine regions to assess their state both in coastal and offshore areas (Crise et al., 2018; Rayner et al., 2019). MOs, although essential for generating knowledge and supporting evidence-based decisions (GOOS, 2019), do not provide a truly holistic view of the marine ecosystems, since they mostly address the oceanographic processes and barely include the ecological ones. Marine Ecological Observatories (MEOs) represent a further advancement of the MOs perspective, since they broaden the spectrum of observing actions to embrace ecological research and monitoring (Carr et al., 2011; Benedetti Cecchi et al., 2018; Manea et al., 2020), recognizing ecological connectivity as one of the main driving forces of marine ecosystems' functioning. Ecological connectivity represents "the degree to which landscapes and seascapes allow species to move freely and ecological processes to function unimpeded" (UNEP, 2019). Due to the intrinsic dynamism that characterizes the marine realm, ecological connectivity is a crucial element, embracing the complex interconnections among the natural processes, the species, their life cycles and the environment (Carr et al., 2003 and 2011; Maxwell et al., 2015; Manea et al., 2019). Within this broad perspective, coherent and operative MEOs are recommended at the European and global level (Benedetti Cecchi et al., 2018; Carr et al., 2011; Duffy et al., 2013; Muelbert et al., 2019). MEOs can deliver great benefits to enhance both the understanding of the marine ecosystems and the assessment of their state and changes over time and space, and the monitoring of the sea for protection and conservation purposes. This can be partly done by integrating data derived from monitoring practices routinely carried out to comply with policy requirements, from long-term ecological research (e.g., LTER data, Acri et al., 2020), from ecological research projects and MPAs monitoring plans, and from enlarging the set of variables measured by observing infrastructures to include biodiversity (e.g., species distribution data through video imagery, Aguzzi et al., 2020).

Among the many attributes and uses MEOs should in- 
corporate (Benedetti Cecchi et al., 2018; Manea et al., 2020), in this paper we focus on the role they should cover to inform marine conservation strategies and to feed European Union (EU) policies and strategies that deal with coastal and marine management. Different jurisdictional instruments are in force in Europe to these purposes, which could take advantages from and contribute to MEOs, in particular the Habitats and Birds directives (EEC 1992 and EC 2009; HD and BD, respectively), the Water Framework Directive (EC 2000; WFD), and the Marine Strategy Framework Directive (EC 2008; MSFD). The European Commission developed in 2017 an action plan (COM(2017) 198 final) to improve the implementation of the Nature directives (HD and BD, respectively) and the related Natura 2000 (N2K) network, which is the main conservation instrument put in place to accelerate the achievement of EU 2020 conservation goals. Among the diverse priorities and related actions to be taken, the plan highlights the need of enhanced and efficient monitoring, as well as of completing the N2K network by filling knowledge gaps to feed the required conservation measures. The WFD and the MSFD were also established to provide legal instruments able to support the conservation and sustainable management of the coastal and marine environment (Kallis and Butler, 2001; Borja et al., 2010; Long 2011), and they strongly rely on monitoring programs proposing operational frameworks and approaches.

Commonalities and synergies among the above-mentioned EU directives are expected, since they all tend to support the achievement of declared conservation goals, and they have been partly analysed from the policy and management perspectives (Rouillard et al., 2018). MEOs, by harmonizing different monitoring frameworks and by collecting and transferring oceanographic and ecological data, can be key knowledge sharing platforms to support the directives and their monitoring plans, enhancing the benefits they could mutually provide to achieve environmental goals.

We present and discuss these issues in the context of the Adriatic Sea, where the ecological observatory "ECOAdS" is under design and development in the framework of the Interreg Italy-Croatia project ECOSS (Observing System in the Adriatic Sea: oceanographic observations for biodiversity; https://www.italycroatia.eu/web/ecoss). Indeed, ECOAdS pilot case will integrate the existing ecological and oceanographic research monitoring with $\mathrm{N} 2 \mathrm{~K}$ conservation strategies, to boost Nature directives and the implementation of N2K network in the marine area of interest for Italy and Croatia. Here we analyse the above-mentioned EU directives, critical instruments able to guide the development of the observatory while supporting the strengthening of transnational cooperation at the basin scale. We bring out the synergies and discrepancies among these legal instruments and build on them ECOAdS as a monitoring platform that may respond and contribute to their requirements, boosting the synergies and overcoming the weaknesses. The main aim is to compare their monitoring approaches to start harmonizing a set of oceanographic and ecological variables to be monitored at the adequate spatial and temporal scales, able to assess the environmental state and the N2K sites' effectiveness, with the additional intent to support the globally recognized Essential Biodiversity Variables (EBVs) and Essential Ocean Variables (EOVs) frameworks (Pereira et al., 2013; MullerKarger et al., 2018). We provide some hints regarding the on-going and future activities that are accompanying the development of this transnational MEO. The proposed approach will incorporate ecological connectivity across spatial and temporal scales to inform the future expansion of N2K network and to support the application of an ecosystem-based approach to conservation (UNEP, 2011).

\section{ECOADS, THE MARINE ECOLOGICAL OBSERVATORY (MEO) OF THE ADRIATIC SEA}

\section{The need of a MEO in the Adriatic}

ECOAdS focuses on the area covered by the Interreg Italy-Croatia program and the adjacent Adriatic Sea, which hosts an outstanding biodiversity and unique environmental conditions, thus delivering multiple ecosystem services and benefits. These include provisioning of food (the Adriatic is among the main fish areas of the Mediterranean Sea, Scarcella et al., 2014) and material, carbon sequestration, water quality regulation and coastal protection, as well as opportunities of leisure and spiritual benefits to people (Depellegrin et al., 2017; Cossarini et al., 2015). However, this marine area is barely covered by Marine Protected Areas (MPAs; Bastari et al., 2016, Manea et al., 2019). Furthermore, it is strongly affected by a huge variety of human activities that have found fertile ground on which to develop, among which fishery, aquaculture, maritime traffic, and land-based activities that affect nutrients and contaminants load reaching the marine environment (Farella et al., 2020; Milliman et al., 2016). For this reason, the Adriatic Sea has been recognized as one of the most impacted area of the Mediterranean Sea (Micheli et al., 2013). The implementation of $\mathrm{N} 2 \mathrm{~K}$ network in the basin is on track with some delay, and it mostly lacks suitable and fulfilled management plans and adequate monitoring programs (Claudet et al., 2020). Nevertheless, several fixed-point observing systems (i.e., pylons, buoys, tide gauges, oceanographic platforms; Fig. 1) are active (Ravaioli et al., 2016; Šepić and Vilibic, 2011; Šepić et al., 2017), providing multidisciplinary data and information automatically and continuously 


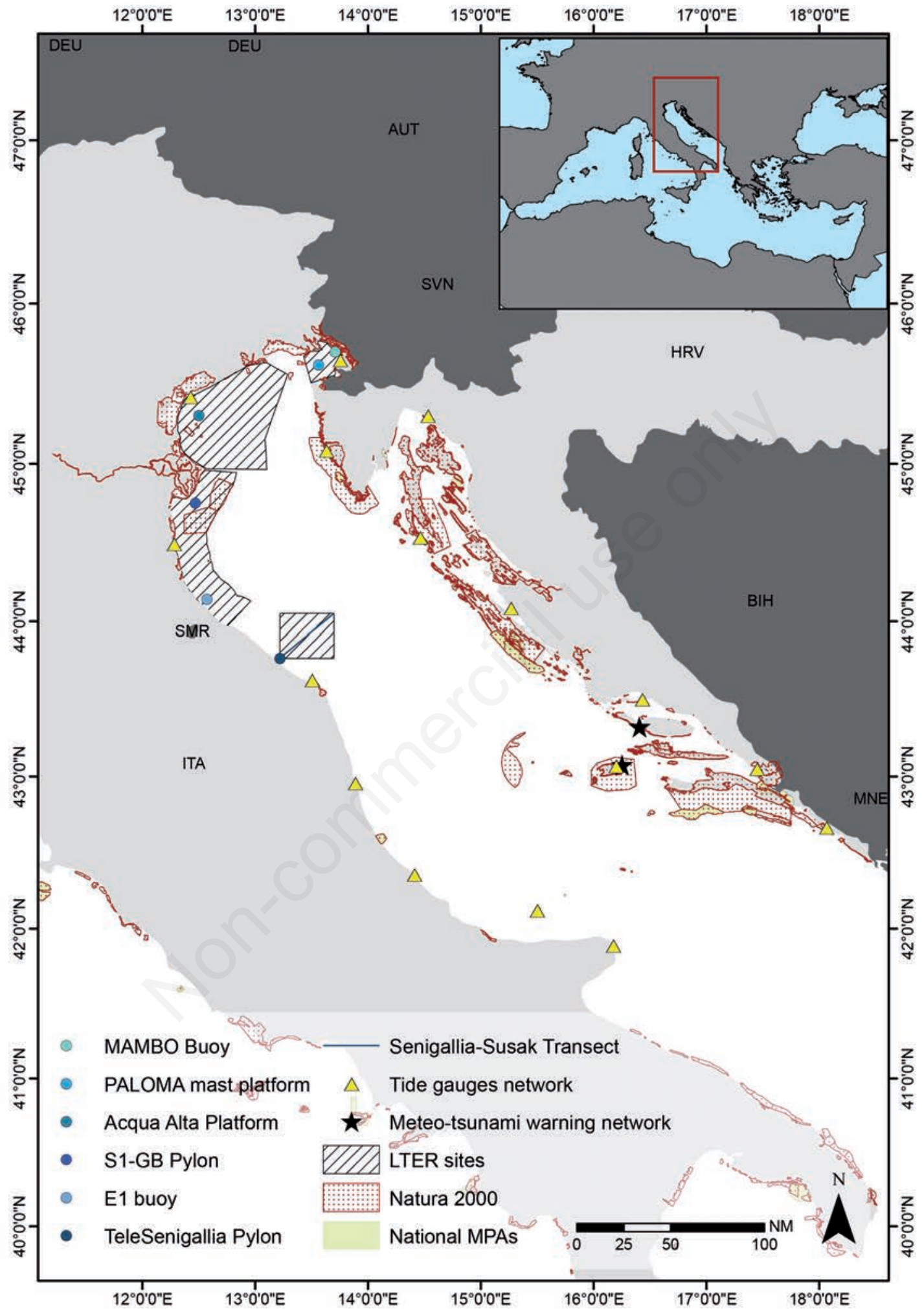

Fig.1. Natura 2000 network, National Marine Protected Areas, sites and fixed point observing systems in the Adriatic Sea. Part of these observing systems is managed by ECOSS project's partners. Data sources: MAPAMED, 2017 (https://www.rac-spa.org/mapamed); Veneto Region web portal (https://bur.regione.veneto.it/BurvServices/Pubblica/DettaglioDgr.aspx?id=426153); Emilia Romagna Region web portal (https://bur.regione.emilia-romagna.it/dettaglio-inserzione?i=dc40e3d31e384e718b81c23cad7946e9); Ravaioli et al., 2016; Meteo-tsunami network (http://jadran.izor.hr/hazadr/index_eng.htm); Tide gauges network (https://www.hhi.hr/en; https://www.mareografico.it); LTER-Italy website (http://www.lteritalia.it/). 
over time. Different monitoring initiatives are also ongoing, as well as specific programs, such as the Italian LongTerm Ecological Research network (LTER-Italy), but at the moment none of these initiatives has a cross-border nature shared between Italy and Croatia. Furthermore, only few of these are operatively supporting the monitoring observations linked to the fulfilment of the EU obligations, despite the wide and varied array of data collected, ranging from those related to the quality of transitional, coastal and marine waters, to the monitoring of target species and habitats (e.g., dolphins, sea turtles, seagrass meadows, coralligenous outcrops). These observing platforms and monitoring schemes operate at various scales, with different aims and maturity levels, lacking an adequate coordination among them, which should connect the local, the regional, up to the whole Adriatic basin scale, in an integrated and coherent observatory.
In this context, ECOAdS gives the opportunity to define and adopt an agreed conceptual framework, to harmonize existing environmental observations, monitoring schemes, and descriptive indicators (Manea et al., 2020; Fig. 2), thus contributing at providing a complete picture of the state of the marine environment, and at supporting transnational cooperation between Italy and Croatia in the Adriatic Sea.

\section{The directives in the design of ECOAdS}

The design phase of ECOAdS entails, as a first crucial step, an accurate comparative analysis among the main EU legal instruments focused on coastal and marine environment protection, namely the WFD, the MSFD, the $\mathrm{HD}$ and $\mathrm{BD}$. For the HB and BD, which act on both terrestrial and aquatic environments, the analysis considers

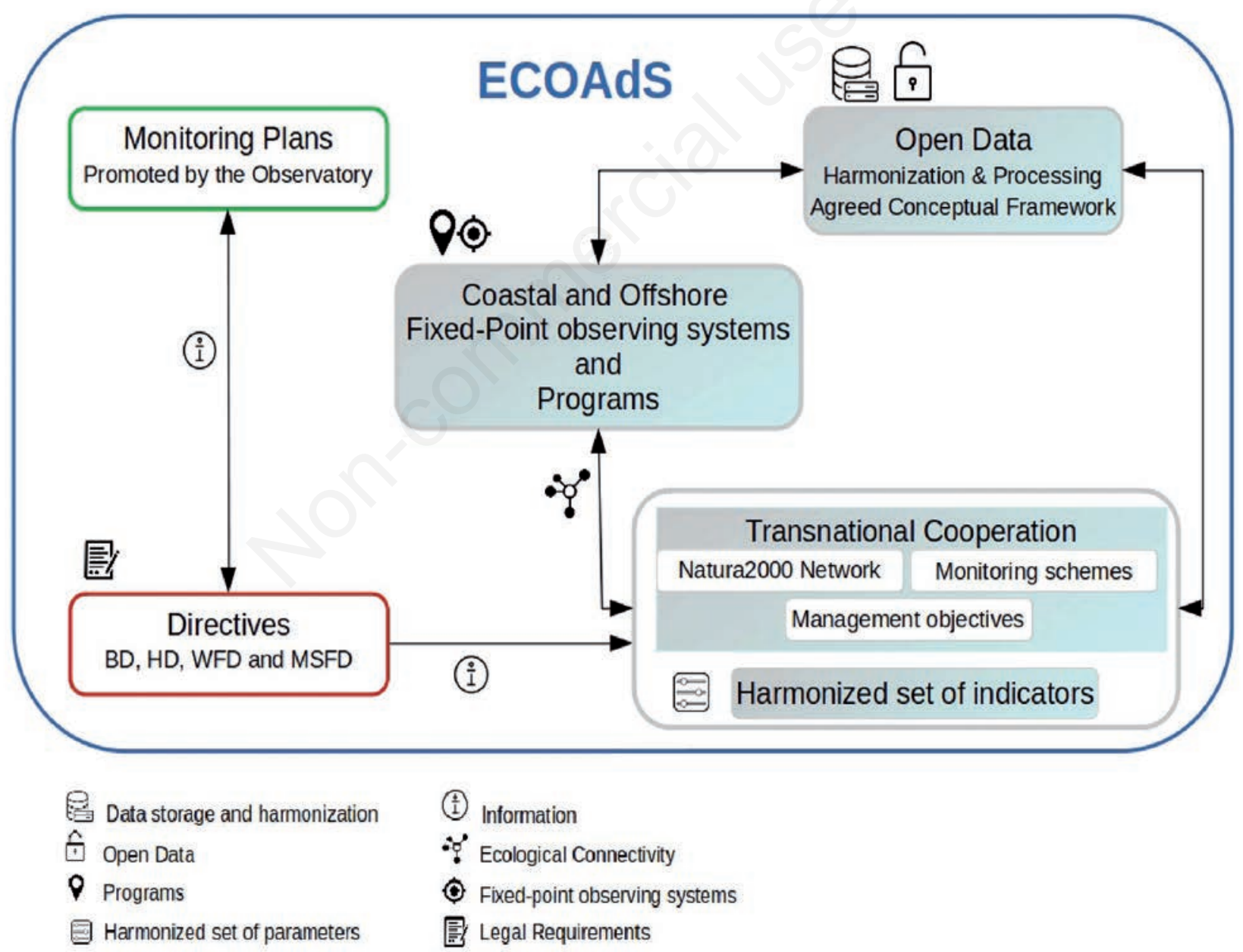

Fig. 2. Schematic view of the essential attributes of ECOAdS to support monitoring programs harmonization. ECOAdS embraces all the observing systems and monitoring programs managed by Italy and Croatia in the Adriatic Sea, by integrating an open science approach and the ecological connectivity concept and providing a harmonized set of monitoring indicators to support transnational cooperation in conservation management. ECOAdS addresses the requirements of the main European directives by linking their monitoring programs to those already existing in the area covered by the Interreg Italy-Croatia program, and to Natura 2000 sites. 
exclusively coastal and marine conservation objectives and targets. The primary aim of such analysis is to identify how ECOAdS could contribute to support the directives' implementation and to overcome possible limitations for the effective monitoring of the aquatic environment. To achieve this, we ascertain the main directives' synergies and commonalities, assessing and highlighting the opportunities that could emerge if synergies would be underpinned, and we individuate potential weaknesses and inconsistencies that should be overcome to support conservation strategies.

Firstly, a short review of the directives is conducted considering key features characterizing them using multiple knowledge sources, mainly coming from official documentation, such as Commission directives, reports and guidelines. The key features are (Tab. 1): i) conservation objectives and targets; ii) approaches adopted to foster conservation initiatives; iii) spatial application; iv) reporting period that guides the evaluation of conservation objectives and targets achievement and of conservation measures effectiveness; v) considerations related to the human uses, the human-derived pressures, and the provision of marine ecosystem services; vi) the criteria and indicators adopted to evaluate conservation objectives and targets achievement; and vii) the indications related to the monitoring strategies. The comparative analysis is firstly built to allow the explicit emergence of the synergies and weaknesses among the legal instruments. Then, the analysis is zoomed in on the monitoring framework entailed within each directive. Finally, the main elements deriving from the analysis are discussed in the context of the future development of ECOAdS.

\section{EU DIRECTIVES FOR MARINE CONSERVATION: DESCRIPTION, COMPARISON AND MONITORING FRAMEWORK}

In Tab. 1 a comparison between the four directives is performed, hinging on the seven features described above. Related insights on synergies, weaknesses and monitoring approaches are presented in the following sections.

\section{Synergies among directives}

Good quality of ecological and environmental state is central for all the directives as they express the need of establishing conservation measures. The HD and BD, by supporting the implementation of the N2K network, are more focused on the in situ protection (Grodzińska-Jurczak et al., 2012; Evans, 2012), while the WFD and MSFD address a broader scale and extend their conservation strategies also beyond the establishment of areas dedicated to conservation. Although not specifically designated for conservation, the WFD shows some rele- vant connections with nature conservation issues. Indeed, it mentions the protection of terrestrial ecosystems and wetlands directly depending on the aquatic ones, clearly referring to the management objectives of $\mathrm{N} 2 \mathrm{~K}$ sites. The MSFD recognizes the important contribution that the establishment of MPAs, including N2K sites, delivers to the achievement of Good Environmental Status (GEnS). Thus, the MSFD promotes the designation of MPAs with the aim of contributing, together with the N2K network, to the achievement of the conservation targets. If the HD and $\mathrm{BD}$ focus on the conservation of target species and habitats, the WFD and the MSFD expand their action by including additionally functional aspects and considering the ecosystems as a conservation unit.

These directives can be considered complementary to each other as together provide an overall normative context for conservation priority objectives at different spatial and ecological levels. The WFD and the MSFD apply within different jurisdictional boundaries, the first being focused on internal and coastal waters (up to $1 \mathrm{~nm}$ ), and the second extending from the coast to offshore areas. Consequently, if appropriately coordinated, they cover the entire water territories supporting the implementation of N2K network also in offshore areas, not leaving gaps amidst aquatic domains. Indeed, N2K sites are spread from the coast to the offshore, and the sites can include a mix of habitats and species being composed by terrestrial, freshwater and marine ecosystems, even crossing the land-sea interface (Kati et al., 2015).

All these legal instruments address the need to ensure a sustainable management of natural resources, by balancing the societal economic needs and the conservation priorities and highlighting the tight interconnections between nature and humans. Explicitly or implicitly, the four directives consider the ecosystem-based approach (Rouillard et al., 2018), they mention natural goods and services, recognizing the critical need of preserving and managing them. While the HD, the BD and the WFD only generically mention the human activities, the MSFD makes an ad hoc analysis of the human-derived pressures and impacts that can negatively affect the marine environment, highlighting the need of addressing all of them through ecosystem-based management measures. Taking advantage of the analysis made by the MSFD, the N2K network managers can be better supported in setting adequate monitoring programs for an improved $\mathrm{N} 2 \mathrm{~K}$ sites management.

Finally, all the directives require monitoring practices to track their goals achievement. The reporting periods of the four directives mainly overlap, except for the WFD that reports every three years instead of six. The provided information entailed within all reporting periods potentially furnishes a complete and comprehensive knowledge framework to inform management and conservation strategies. 


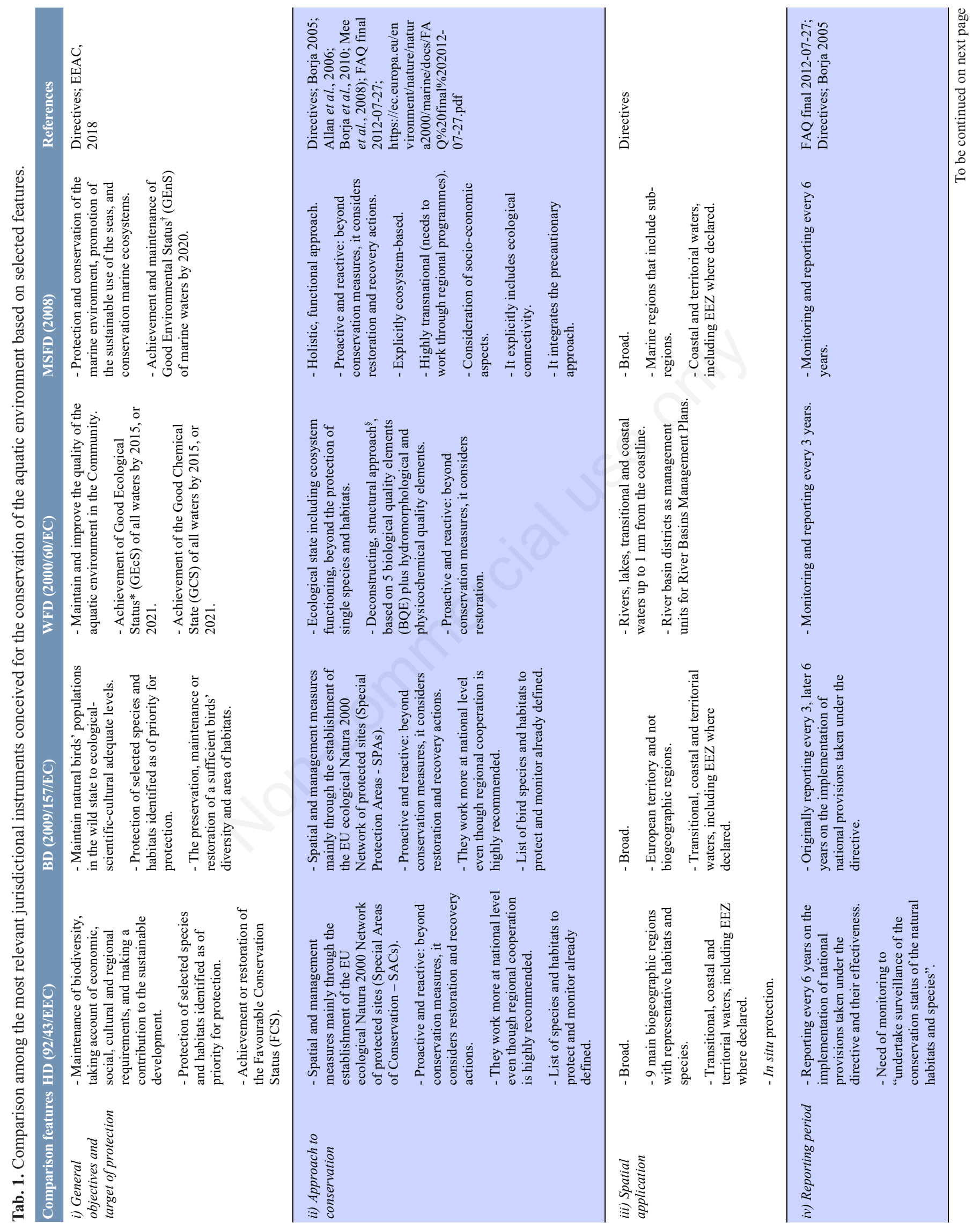




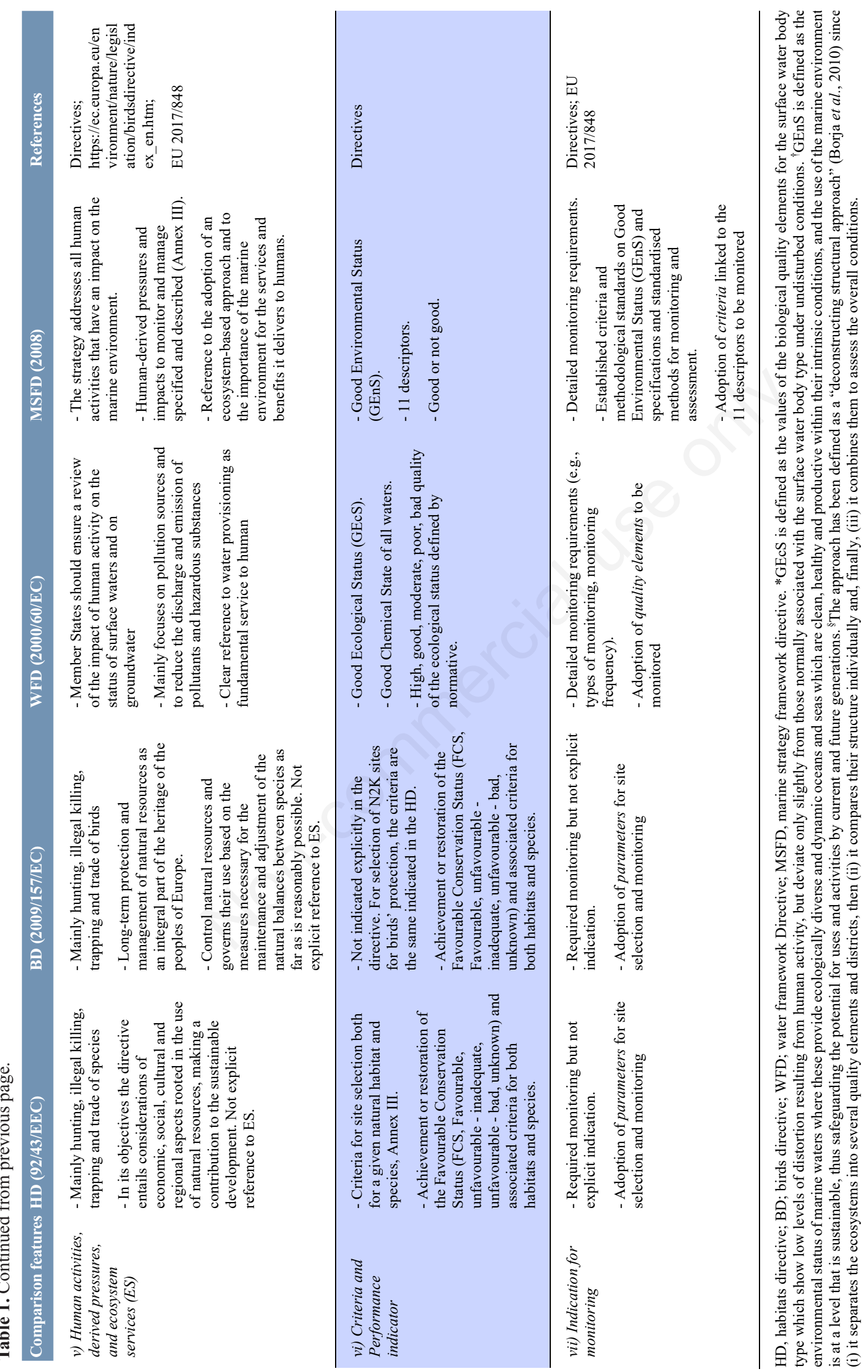




\section{Weaknesses among directives}

The comparative analysis of the four directives evidences some weaknesses related to different aspects of their implementation. The absence of precise guidelines for their implementation hampers the possibility of setting up a coherent regional-based ecological network of N2K sites. In addition, management plans related to N2K sites are not mandatory and they are often absent (Claudet et al., 2020): this greatly affects the conservation effectiveness, since adequate monitoring activities are not set up, thus leaving the sites often unmanaged and unmonitored, without the possibility to assess the achievement of the conservation objectives they were set for.

Nature directives may anyway fail in achieving their aims, if they focus only on specific habitats and species, overlooking the overall environmental complexity and ecological connectivity. As for the WFD, the deconstructing and structural approach (see Tab. 1; Borja et al., 2010) might also weaken the possibility of thoroughly assessing the ecological status of the aquatic environment, by not adequately addressing connectivity aspects. This is something that the MSFD tries to avoid by proposing a fully holistic and ecosystem-based approach. However, an effective operationalization of such an approach within all the here considered legislative frameworks is still weak (O'Hagan, 2020), despite it would be greatly beneficial to underpin a better protection of the marine environment at the ecosystem level.

The MSFD and WFD, despite presenting detailed monitoring requirements, do not give indication to Member States (MS) on threshold values or baselines to be considered when assessing the level of GEnS and Good Ecological Status (GEcS), respectively. Difficulties in establishing current extent and quality of habitats and populations, and in setting acceptable limits to degradation against unknown levels of natural variation, may strongly affect directives' implementation and lead to incoherency among MS assessment results (Dodds et al., 2010).

Within the diverse monitoring frameworks covered by the four directives there is a noticeable heterogeneity in the terminology used that may create confusion to MS and N2K sites' managers to define and setting up coherent monitoring strategies. Therefore, we highlight the need to harmonize terminology on criteria, quality elements and parameters (see Tab. 1). With ECOAdS, we make a first attempt to define coherent relationships among the considered directives (Tables S2-S5).

\section{Monitoring approaches}

The HD and BD address the conservation of target species and habitats, thus the parameters they consider for site selection and monitoring are related to the conservation status of these targets, comprising quantitative (range, area, population size) as well as qualitative (struc- ture and functions) criteria plus a forecast for the future ('future prospects' parameter) (European Commission, 2016a). However, no guidance on how to monitor species and habitats is provided. Only guidelines for the reporting of the necessary information for the assessment of sites' state were delivered (DG Environment, 2017). The WFD, differently from the Nature directives, provides specific guidelines for monitoring the quality status of water bodies. Indeed, it presents very detailed monitoring requirements for both surface and groundwater and lists several steps to carry out for effective monitoring: design of surveillance, operational and investigative monitoring, frequency of monitoring, additional monitoring requirements for protected areas, standards for monitoring of quality elements. The WFD labels the parameters to be adopted for monitoring as quality elements (biological, hydro-morphological, and physico-chemical). This directive asks for a systematic "review of the impact of human activity on the status of surface waters and groundwater". However, similarly to the Nature directives, it does not specifically list the human activities and related pressures to be considered and managed. The MSFD articulates the GEnS in eleven descriptors (Table S1) and associated criteria by addressing both species and habitats of priority for conservation. The European Commission, in 2017, laid down criteria and methodological standards to give common guidelines to MS to monitor advances towards the achievement of GEnS through the EU 2017/848. Another document was delivered concurrently, the EU 2017/845, to better guide the MS during the second cycle of implementation of their marine strategies. MS should take into account pressures or impacts of human activities in each marine region or subregion, having regard to the indicative lists set out in Annex III.

Tables S2-S5 report the comparative analysis focalized on the descriptive indicators of the four directives. We use the term descriptive indicators as a common term to refer to the $\mathrm{HD}$ and $\mathrm{BD}$ parameters, the quality elements of the WFD, and the MSFD criteria. Since the MSFD is the most recent directive and adopts the most holistic approach to monitoring, the comparison of the indicators is developed starting from its criteria. Criteria are compared with the descriptive indicators of the other directives to find coherent matches to make a first harmonization attempt.

It is noticeable that there is not a complete and specific correspondence between the diverse descriptive indicators, which differ among directives as each jurisdictional instrument addresses specific conservation targets despite their overall shared objectives. Indeed, they are aggregated differently: the MSFD criteria are articulated upon its descriptors, which identify specific environmental performances (descriptors 1-4) explicitly considering also the human-induced pressures sphere (descriptors 5-11). Inter- 
estingly, the MSFD is the only directive that reflects, even if indirectly, on species interactions through descriptor 4 , related to the food web and the elements from which this is composed. Indeed, criteria related to D4 find almost no correspondence with the descriptive indicators of the other directives.

The WFD presents a rich set of specific quality elements related to the water bodies' characteristics, including also inland (e.g., lakes and rivers) and transitional water ecosystems (e.g., lagoons), which are not covered by the MSFD. The WFD specifically addresses only some target communities, i.e., macrophytes, phytobenthos, phytoplankton, invertebrates, and fish. It does not include pelagic population beyond phytoplankton and fish components (e.g., cephalopods, reptiles and marine mammals). However, some WFD quality elements find a good correspondence with different MSFD criteria, as for example those related to the phytoplankton component and linked to D5. Also several WFD chemical and physical elements closely match (e.g., all elements related to the hydrographical conditions) with MSFD criteria, even though the terminology and the level of specificity of the indicators are different.

Regarding the HD and $\mathrm{BD}$, it is possible to observe a stronger correspondence of their parameters with criteria related to MSFD Descriptor 1 "Biodiversity is maintained". For instance, both Nature directives find correspondence with three criteria related to D1: D1C2 population abundance, D1C3 demographic characteristics, and D1C4 distributional range and pattern. The corresponding parameter in HD is "population dynamics of animal and plant species", while in BD is "trends and variations in population for species". Both Nature directives do not consider the set of chemical and physical indicators included in the other two directives (MSFD and WFD), being mainly focalized on target species and habitats preservation.

Although the HD does not look at all species occurring in water bodies (i.e., the aquatic community as a whole), being mainly focused on the conservation status of selected species and habitats, there are some quality elements defined by the WFD and some criteria defined by the MSFD that - if jointly monitored - can be shared and beneficial for N2K sites monitoring, in particular for those monitoring activities that require standardized methodological approaches (e.g., chl-a measurements and nutrient analysis).

\section{FUTURE PERSPECTIVE FOR ECOADS AS TRANSNATIONAL MEO}

Cross-border cooperation to monitor the marine environment has been highlighted as crucial to support comprehensive monitoring and effective conservation and management (Stelzenmüller et al., 2013; Azzurro et al., 2014). The need of such an approach has become greater with time since EU member states have been called to integrate the planning and management of their territorial waters into a transboundary approach by year 2020 (European Commission 2014). Cross-border conservation initiatives have been suggested as powerful tools to foster a balance between conservation and exploitation of natural resources, as well as to reflect the ecological boundaries dictated by marine connectivity (Mackelworth, 2012; Costello and Molina, 2021). In the Adriatic Sea, where $\mathrm{N} 2 \mathrm{~K}$ network is under further implementation, several studies have been developed to guide marine conservation initiatives and ecosystem-based management, also in transboundary contexts (Gissi et al., 2018; Manea et al., 2019; Drius et al., 2019; Farella et al., 2020 among others). The establishment of the transnational MEO ECOAdS, shared between Italy and Croatia, represents an opportunity for setting up a common platform where to implement the harmonization and integration of marine environment monitoring to inform both the local and basin-scale conservation strategies that are underway (Bax et al., 2018). Indeed, in this area an integrated system that coordinates the diverse monitoring efforts is absent (Manea et al., 2020).

Here we focus on the monitoring frameworks entailed within the Nature directives and the WFD and MSFD carried out in the area. We bring into light many synergies among them as a base for a comprehensive monitoring of the marine environment through space and time to inform the development of ECOAdS. These synergies are crucial since the monitoring under the Nature directives is weakly implemented, often for shortcomings of dedicated funds. We indicate as key the WFD and MSFD monitoring programs to investigate $\mathrm{N} 2 \mathrm{~K}$ sites environmental state, also considering that (as evidenced in section "ECOAdS"), most of HD and BD target species and habitats are monitored under the MSFD. Thus, wherever possible, joint monitoring programs should be arranged to include priority conservation sites within their spatial footprints, also to avoid neglecting some marine areas, especially at the interfaces (e.g., land-sea, coastal-offshore waters). This would be particularly relevant to integrate ecological connectivity information in monitoring strategies, even beyond conservation sites to fit a transboundary context (Portman and Teff-Seker, 2017). ECOAdS is conceived as an instrument able to boost such coordination, thus favouring the integration of these monitoring efforts at multiple scales and the availability of observatory data to inform management and conservation strategies at the Adriatic Sea region.

As a key principle, ECOAdS addresses the incorporation of ecological connectivity to support the adoption of an ecosystem-based approach to management (Jonsson et al., 2021). The legal documentation considered in this study supports this necessity, despite directives barely entail eco- 
logical connectivity aspects, thus orienting the implementation of this approach only weakly (O'Hagan, 2020). For instance, our analysis points out that the trophic webs in the marine environment are extremely poorly characterized by the existing monitoring programs, even though they are an integral part of the connectivity concept (Dias et al., 2016), in combination with the state of the species and the whole oceanographic context. To address such weakness, ECOAdS aims at developing a shared set of monitoring indicators entailing both ecological and oceanographic data, giving relevance to connectivity aspects. Indeed, only a monitoring strategy implemented and coordinated at the basin scale, and addressing processes like larvae dispersal and genetic flow, nutrient fluxes, migration patterns and movement in response to environmental variability and climate change and human-induced pressures (Toonen et al., 2011; She et al., 2016) can support the incorporation of ecological connectivity in marine monitoring. Furthermore, starting from the MSFD indications, ECOAdS will entail the monitoring of anthropogenic pressures' sources and footprint. Indeed, human pressure monitoring is essential to inform management and measure conservation outcomes (Dunham et al., 2020).

The harmonization of the terminology used to indicate monitored parameters and variables is an additional purpose of ECOAdS, since the heterogeneous use of terms can severely hamper an effective coordination between monitoring schemes also linked to the fulfilment of the different EU obligations. This effort is grounded on the awareness that the absence of harmonized terminology leads to obstacles in data integration and interpretation, thus inducing redundant research and monitoring efforts and slowing down the scientific cooperation and progress (Berners-Lee et al., 1999). The adoption of a shared and agreed set of terms to refer to monitoring indicators, linked together in a hierarchical and relational network within the so called "thesauri" (ISO, 2011, 2013) - can help overcome the ambiguities associated with data markup and allow digital interpretation and information storage of records (IOC UNESCO, 2019), thus improving the interoperability and data exchange. As an outcome, in ECOAdS a harmonized set of monitoring indicators will be distilled starting from those proposed by the discussed directives (Tables S1-S5), and it will be integrated in an interactive web application to support the setting up of the monitoring activities needed in selected Adriatic N2K sites. The indicators will be further elaborated according to selection criteria, such as their policy relevance, sensitivity to change and feasibility, to evaluate their suitability and priority level for monitoring (Schmeller et al., 2018). This set of indicators will also support the EBV and EOV frameworks, which have been developed to address the need to track progress towards SDGs and conservation goals (Reyers et al., 2017).
ECOAdS, playing the role of collector of different monitoring data sources, can contribute to the ongoing building of long-term datasets to inform the definition of reliable threshold values useful to map and assess the state of the marine environment. Moreover, the adoption of the open science approach and the FAIR principles (European Commission 2016b) are addressed to boost transnational data sharing through the implementation of a web portal (Manea et al. 2020) acting as a unique access point to the data collected by the observatory.

ECOAdS represents a real opportunity to better operationalize the ecosystem-based approach, since it contributes to implement a holistic approach to marine monitoring and conservation. Indeed, within its framework, a core part is taken by the engagement of stakeholders and right holders who might contribute to co-produce knowledge related to the marine environment and the use of its resources. ECOAdS is not only at the interface between scientific research and environmental management, but also between the scientific world and the civil society. Community-based monitoring has been highlighted as a possible effective approach to engage in future monitoring practices (Turricchia et al., 2020). Running a multi-level participatory process is at the base of the development of ECOAdS, to design its structure and nourish its conceptual framework. In addition, this process can be of great benefit for the implementation of EU directives, since stakeholders' contribution is crucial to put into practice environmental policies and to achieve marine conservation goals.

\section{ACKNOWLEDGMENTS}

All the authors acknowledge the ECOSS project (Observing System in the Adriatic Sea: oceanographic observations for biodiversity), an EU 2014-2020 Interreg V-A Italy-Croatia CBC programme ID number 10042301.

Corresponding author: caterina.bergami@ismar.cnr.it

Key words: Marine ecological observatories; transboundary coordination; ECOAdS; Adriatic Sea; ECOSS project.

Conflict of interest: The authors declare that they have no known competing financial interests or personal relationships that could have appeared to influence the work reported in this paper.

Received: 15 April 2021.

Accepted: 24 June 2021.

This work is licensed under a Creative Commons Attribution NonCommercial 4.0 License (CC BY-NC 4.0).

${ }^{\circ}$ Copyright: the Author(s), 2021

Licensee PAGEPress, Italy

Advances in Oceanography and Limnology, 2021; 12:9811

DOI: 10.4081/aiol.2021.9811 


\section{REFERENCES}

Acri F, Bastianini M, Bernardi Aubry F, Camatti E, Boldrin A, et al., 2020. A long-term (1965-2015) ecological marine database from the LTER-Italy Northern Adriatic Sea site: plankton and oceanographic observations. Earth Syst. Sci. Data 12:215-230.

Aguzzi J, Iveša N, Gelli M, Costa C, Gavrilovic A, et al., 2020. Ecological video monitoring of Marine Protected Areas by underwater cabled surveillance cameras. Mar. Pol. 119:104052.

Allan IJ, Vrana B, Greenwood R, Mills GA, Roig B, Gonzalez C, 2006. A "toolbox" for biological and chemical monitoring requirements for the European Union's Water Framework Directive. Talanta 69:302-322.

Azzurro E, Ben Souissi SJ, Boughedir W, Castriota L, Deidun A, et al. 2014. The Sicily Strait: a transnational observatory for monitoring the advance of non indigenous species. Biol. Mar. Mediterr. 21:105-106.

Berners-Lee T, Fischetti M, 2000. Weaving the web: The original design and ultimate destiny of the world wide web by its inventor. Harper: San Francisco.

Bastari A, Micheli F, Ferretti F, Pusceddu A, Cerrano C, 2016. Large marine protected areas (LMPAs) in the Mediterranean Sea: the opportunity of the Adriatic Sea. Mar. Pol. 68:165-177.

Bax NJ, Appeltans W, Brainard R, Duffy JE, Dunstan P, et al., 2018. Linking capacity development to GOOS monitoring networks to achieve sustained ocean observation. Front. Mar. Sci. 5:346.

Benedetti-Cecchi L, Crowe T, Boehme L, Boero F, Christensen A, et al., 2018. Strengthening Europe's capability in biological ocean observations. Future Science Brief 3 of the European Marine Board: Ostend. Available from: https://marineboard.eu/sites/marineboard.eu/files/public/pub lication/EMB_FSB3_Biological_Ocean_Observation.pdf

Biermann F, Kanie N, Kim RE, 2017. Glōbal governance by goal-setting: the novel approach of the UN Sustainable Development Goals. Curr. Opin. Env. Sust. 26-27:26-3.

Borja A, 2005. The European Water Framework Directive: a challenge for nearshore, coastal and continental shelf research. Cont. Shelf Res. 25:1768-1783.

Borja Á, Elliott M, Carstensen J, Heiskanen AS, van de Bund W, 2010. Marine management-towards an integrated implementation of the European Marine Strategy Framework and the Water Framework Directives. Mar. Pollut. Bull. 60:2175-2186.

Carr MH, Neigel JE, Estes JA, Andelman S, Warner RR, Largier JL, 2003. Comparing marine and terrestrial ecosystems: implications for the design of coastal marine reserves. Ecol. Appl. 13:90-107.

Carr MH, Woodson CB, Cheriton OM, Malone D, McManus MA, Raimondi PT, 2011. Knowledge through partnerships: integrating marine protected area monitoring and ocean observing systems. Front. Ecol. Environ. 9:342-350.

Claudet J, Loiseau C, Sostres M, Zupan M, 2020. Underprotected marine protected areas in a global biodiversity hotspot. One Earth 2:380-384.

Cossarini G, Querin S, Solidoro C, 2015. The continental shelf carbon pump in the northern Adriatic Sea (Mediterranean Sea): Influence of wintertime variability. Ecol. Model. 314:118-134.
Costello C, Molina R, 2021. Transboundary marine protected areas. Resour. Energy Econ. 65;101239.

Crise A, Ribera d'Alcalà M, Mariani,P, Petihakis G, Robidart J, et al., 2018. A conceptual framework for developing the next generation of Marine OBservatories (MOBs) for science and society. Front. Mar. Sci. 5:318.

DG Environment, 2017. Reporting under Article 17 of the Habitats Directive: Explanatory notes and guidelines for the period 2013-2018. Available from: http:/www.reportingdirettivahabitat.it/public/documents/documenti\%20ufficiali\%20europei/Reporting\%20guidelines.pdf

Dias E, Morais P, Cotter AM, Antunes C, Hoffman JC, 2016. Estuarine consumers utilize marine, estuarine and terrestrial organic matter and provide connectivity among these food webs. Mar. Ecol. Prog. Ser. 554:21-34.

Dodds WK, Clements WH, Gido K, Hilderbrand RH, King RS, 2010. Thresholds, breakpoints, and nonlinearity in freshwaters as related to management. J. N. Am. Benthol. Soc. 29:988-997.

Drius M, Bongiorni L, Depellegrin D, Menegon S, Pugnetti A, Stifter S, 2019. Tackling challenges for Mediterranean sustainable coastal tourism: An ecosystem service perspective. Sci. Total Environ. 652:1302-1317.

Duffy JE, Amaral-Zettler LA, Fautin DG, Paulay G, Rynearson TA, et al., 2013. Envisioning a marine biodiversity observation network. Bioscience 63:350-361.

Dunham A, Dunham JS, Rubidge E, Iacarella JC, Metaxas A, 2020. Contextualizing ecological performance: Rethinking monitoring in marine protected areas. Aquat. Conserv. 30:2004-2011.

European Commission, 1992. Council Directive 92/43/EEC of May 211992 on the conservation of natural habitats and of wild fauna and flora. Official Journal of the European Communities.

European Commission, 2000. Directive 2000/60/EC of the European Parliament and of the Council of 23 October 2000 establishing a framework for Community action in the field of water policy (Water Framework Directive). Official Journal of the European Union.

European Commission, 2008. Directive 2008/56/EC of the European Parliament of the Council of 17 June 2008 establishing a framework for community action in the field of marine environmental policy (Marine Strategy Framework Directive). Official Journal of the European Union.

European Commission, 2009. Directive 2009/147/EC of the European Parliament and of the Council of 30 November 2009 on the conservation of wild birds. Official Journal of the European Union.

European Commission, 2012. FAQ final 2012-07-27. Links between the Marine Strategy Framework Directive (MSFD 2008/56/EC) and the Nature Directives (Birds Directive 2009/147/EEC (BD) and Habitats Directive 92/43/EEC (HD)) https://ec.europa.eu/environment/nature/natura2000/marine/d ocs/FAQ\%20final\%202012-07-27.pdf

European Commission, 2014. Report from the Commission to the European Parliament, the Council, the European Economic and Social Committee of the Regions concerning the governance of macroregional strategies. Document 52014DC0284.

European Commission, 2016a. Reporting under Article 17 of the Habitats Directive. Report format for the period 2013- 
2018, Final Version - November 2016. Available from: http://cdr.eionet.europa.eu/help/habitats_art17/index html

European Commission, 2016b. European Commission: Open innovation, open science, open to the world - a vision for Europe. Available from: https://op.europa.eu/en/publicationdetail/-/publication/3213b335-1cbc-11e6-ba9a-01aa75ed71a1/ language-en

European Commission, 2017. Commission Directive 2017/845 of 17 May 2017 amending Directive 2008/56/EC of the European Parliament and of the Council as regards the indicative lists of elements to be taken into account for the preparation of marine strategies. Document 32017L0845.

European Commission, 2017. Commission Decision 2017/848 of 17 May 2017 laying down criteria and methodological standards on good environmental status of marine waters and specifications and standardised methods for monitoring and assessment, and repealing Decision 2010/477/EU. Document 32017D0848.

European Commission, 2017. Communication from the commission to the european parliament, the council, the European economic and social committee and the committee of the regions an Action Plan for nature, people and the economy. Available from: https://op.europa.eu/en/publication-detail//publication/bb26e7d1-2b26-11e7-9412-01aa75ed71a1

European Environment and Sustainable Development Advisory Councils (EEAC), 2018. Working Group on Fresh Water Affair 2018. The EU Water Framework Directive. Results to date and outlook for the future. Available from: https://eeac. eu/wp-content/uploads/2018/09/The-EU-Water-FrameworkDirective-Results-to-date-and-outlook-for-the-future.pdf

Evans, D, 2012. Building the European union's Natura 2000 network. Nat. Conserv. 1:11.

Farella G, Menegon S, Fadini A, Depellegrin D, Manea E, et al., 2020. Incorporating ecosystem services conservation into a scenario-based MSP framework: An Adriatic case study. Ocean. Coast. Manag. 193:105230.

Gissi E, McGowan J, Venier C, Di Carlo D, Musco F, et al., 2018. Addressing transboundary conservation challenges through marine spatial prioritization. Conserv. Biol. 32:1107-1117.

Grodzińska-Jurczak M, Strzelecka M, Kamal S, Gutowska J, 2012. Effectiveness of Nature Conservation-a case of Natura 2000 sites in Poland. In: Sladonja B (ed.), Protected area management. IntechOpen.

Intergovernmental Oceanographic Commission of UNESCO, 2019. Ocean Data Standards, Vol.4: SeaDataNet Controlled Vocabularies for describing Marine and Oceanographic Datasets - A joint Proposal by SeaDataNet and ODIP projects. (IOC Manuals and Guides, 54, Vol. 4.) 31 pp. (IOC/2019/MG/54 Vol.4). Ostend: IODE/UNESCO.

International Organization for Standardization, 2011. ISO 25964-1:2011. Information and Documentation - Thesauri and Interoperability with Other Vocabularies - Part 1: Thesauri for Information Retrieval. Geneva: International Organization for Standardization.

International Organization for Standardization, 2013. Norm ISO 25964-2:2013. Information and Documentation - Thesauri and Interoperability with Other Vocabularies - Part 2: Interoperability with Other Vocabularies. Geneva: International Organization for Standardization.
Jonsson PR, Hammar L, Wåhlström I, Pålsson J, Hume D, et al., 2021. Combining seascape connectivity with cumulative impact assessment in support of ecosystem $\square$ based marine spatial planning. J. Appl. Ecol. 58:576-586.

Kallis G, Butler D, 2001. The EU water framework directive: measures and implications. Water Pol. 3:125-142.

Kati V, Hovardas T, Dieterich M, Ibisch PL, Mihok B, Selva N, 2015. The challenge of implementing the European network of protected areas Natura 2000. Conserv. Biol. 29:260-270.

Long R, 2011. The Marine Strategy Framework Directive: a new European approach to the regulation of the marine environment, marine natural resources and marine ecological services. J. Energy Nat. Resour. Law 29:1-44.

Mack L, Attila J, Aylagas E, Beermann A, Borja A, et al., 2020. A synthesis of marine monitoring methods with the potential to enhance the status assessment of the Baltic Sea. Front. Mar. Sci. 7:823.

Mackelworth P, 2012. Peace parks and transboundary initiatives: implications for marine conservation and spatial planning. Conserv. Lett. 5:90-98.

Manea E, Di Carlo D, Depellegrin D, Agardy T, Gissi E, 2019. Multidimensional assessment of supporting ecosystem services for marine spatial planning of the Adriatic Sea. Ecol. Indic. 101:821-837.

Manea E, Bongiorni L, Bergami C, Pugnett, A, 2020. Challenges for marine ecological observatories to promote effective GMS of Natura 2000 network. The case study of ECOAdS in the Adriatic Sea, p. 23-39. In: Alfaré L, Ruoss E (eds.), Governing future challenges in protected areas. CNR Edizioni.

Maxwell SM, Hazen EL, Lewison RL, Dunn DC, Bailey H, et al., 2015. Dynamic ocean management: Defining and conceptualizing real-time management of the ocean. Mar. Pol. 58:42-50.

McQuatters-Gollop A, Mitchell I, Vina-Herbon C, Bedford J, Addison PFR, et al., 2019. From science to evidence-how biodiversity indicators can be used for effective marine conservation policy and management. Front. Mar. Sci. 6:109.

Mee LD, Jefferson RL, Laffoley DDA, Elliott M, 2008. How good is good? Human values and Europe's proposed Marine Strategy Directive. Mar. Pollut. Bull. 56:187-204.

Micheli F, Halpern BS, Walbridge S, Ciriaco S, Ferretti F, et al., 2013. Cumulative human impacts on Mediterranean and Black Sea marine ecosystems: assessing current pressures and opportunities. PloS One 8:e79889.

Milliman JD, Bonaldo D, Carniel S, 2016. Flux and fate of riverdischarged sediments to the Adriatic Sea. Adv. Oceanogr. Limnol. 7:5899.

Miloslavich P, Bax NJ, Simmons SE, Klein E, Appeltans W, et al., 2018. Essential ocean variables for global sustained observations of biodiversity and ecosystem changes. Glob. Change Biol. 24:2416-2433.

Muelbert JH, Nidzieko NJ, Acosta AT, Beaulieu SE, Bernardino AF, et al., 2019. ILTER-The International Long-Term Ecological Research Network as a platform for global coastal and ocean observation. Front. Mar. Sci. 6:527.

Muller-Karger FE, Miloslavich P, Bax NJ, Simmons S, Costello MJ, et al., 2018. Advancing marine biological observations and data requirements of the complementary essential ocean variables (EOVs) and essential biodiversity variables (EBVs) frameworks. Front. Mar. Sci. 5:211. 
O'Hagan AM, 2020. Ecosystem-based management (EBM) and ecosystem services in EU law, policy and governance, $p$. 353-372. In: O'Higgins T, Lago M and DeWitt T (eds.), Ecosystem-based management, ecosystem services and aquatic biodiversity. Cham: Springer.

Pereira HM, Ferrier S, Walters M, Geller GN, Jongman RHG, et al., 2013. Essential biodiversity variables. Science 339:277-278.

Portman ME, Teff-Seker Y, 2017. Factors of success and failure for transboundary environmental cooperation: projects in the Gulf of Aqaba. J. Environ. Policy Plan 19:810-826.

Rayner R, Jolly C, Gouldman C, 2019. Ocean observing and the blue economy. Font. Mar. Sci. 6:330.

Ravaioli M, Bergami C, Riminucci F, Langone L, Cardin V, et al., 2016. The RITMARE Italian Fixed-Point Observatory Network (IFON) for marine environmental monitoring: a case study. J. Oper. Oceanogr. 9:202-214.

Reyers B, Stafford-Smith M, Erb KH, Scholes RJ, Selomane O, 2017. Essential variables help to focus sustainable development goals monitoring. Curr. Opin. Environ. Sustain. 26:97105.

Rouillard J, Lago M, Abhold K, Röschel L, Kafyeke T, et al., 2018. Protecting aquatic biodiversity in Europe: How much do EU environmental policies support ecosystem-based management? Ambio 47:15-24.

Scarcella G, Grat, F, Raicevich S, Russo T, Gramolini R, et al., 2014. Common sole in the northern and central Adriatic Sea: spatial management scenarios to rebuild the stock. J. Sea Res. 89:12-22.

Schmeller DS, Weatherdon LV, Loyau A, Bondeau A, Brotons $\mathrm{L}$, et al., 2018. A suite of essential biodiversity variables for detecting critical biodiversity change. Biol. Rev. 93:55-71. She J, Allen I, Buch E, Crise A, Johannessen A, et al., 2016. Developing European operational oceanography for Blue Growth, climate change adaptation and mitigation, and ecosystem-based management. Ocean Sci 12:953-976.

Šepić J, Vilibic I, 2011. The development and implementation of a real-time meteotsunami warning network for the Adriatic Sea. Nat. Hazards Earth Syst. Sci. 11:83-91.

Šepić J, Vilibic I, Denamiel C, Mihanović H, Muslim S, et al., 2017. Towards understanding and operational early warning of the Adriatic meteotsunamis: Project MESSI. Proceedings 1st Workshop on Waves, Storm Surges and Coastal Hazards.

Stelzenmüller V, Breen P, Stamford T, Thomsen F, Badalamenti F, et al., 2013. Monitoring and evaluation of spatially managed areas: a generic framework for implementation of ecosystem based marine management and its application. Mar. Pol. 37:149-164.

Toonen RJ, Andrews KR, Baums IB, Bird CE, Concepcion GT, et al., 2011. Defining boundaries for ecosystem-based management: a multispecies case study of marine connectivity across the Hawaiian Archipelago. J. Mar. Biol. 2011:460173.

United Nations Environment Programme (UNEP), 2011. Taking steps toward marine and coastal ecosystem-based management - An introductory guide. Available from: https://www. unep.org/resources/report/taking-steps-toward-marine-andcoastal-ecosystem-based-management-introductory

United Nations Environment Programme (UNEP), 2019. Frontiers 2018/19: Emerging issues of environmental concern. Available from: https:/www.unep.org/resources/frontiers201819-emerging-issues-environmental-concern 